\title{
The reaction force. A scalar property to characterize reaction mechanisms
}

\author{
Jorge Martínez • Alejandro Toro-Labbé
}

Published online: 21 January 2009

(C) Springer Science+Business Media, LLC 2009

\section{Erratum to: J Math Chem \\ DOI 10.1007/s10910-008-9478-0}

Figure 8 in the original article featured an horizontal scale ranging from 0 to 1 , but in fact it should range from 1 to 0 . The revised figure is shown here.

The online version of the original article can be found under doi:10.1007/s10910-008-9478-0.

J. Martínez ( $\square)$

Materials Science Group, Southeastern Pacific Research Institute for Advanced Technologies (SEPARI), Universidad Técnica Federico Santa María, Avenida España 1680, Edificio T, Casilla 110 V, Valparaíso, Chile

e-mail: jorge.martinez@separi.cl

\section{A. Toro-Labbé}

Laboratorio QTC, Departamento de Química Física, Facultad de Química, Pontificia Universidad Católica de Chile, Casilla 306, Correo 22, Santiago, Chile

e-mail: atola@uc.cl 
Fig. 8 Relationships between $\{\delta, \mathbf{r}, \varepsilon\}$ and IRC; positions of reactant, transition state and product along the intrinsic reaction coordinate, IRC (or reduced reaction coordinate $\xi$ ) are indicated as $\mathbf{R}$, TS and $\mathbf{P}$, respectively
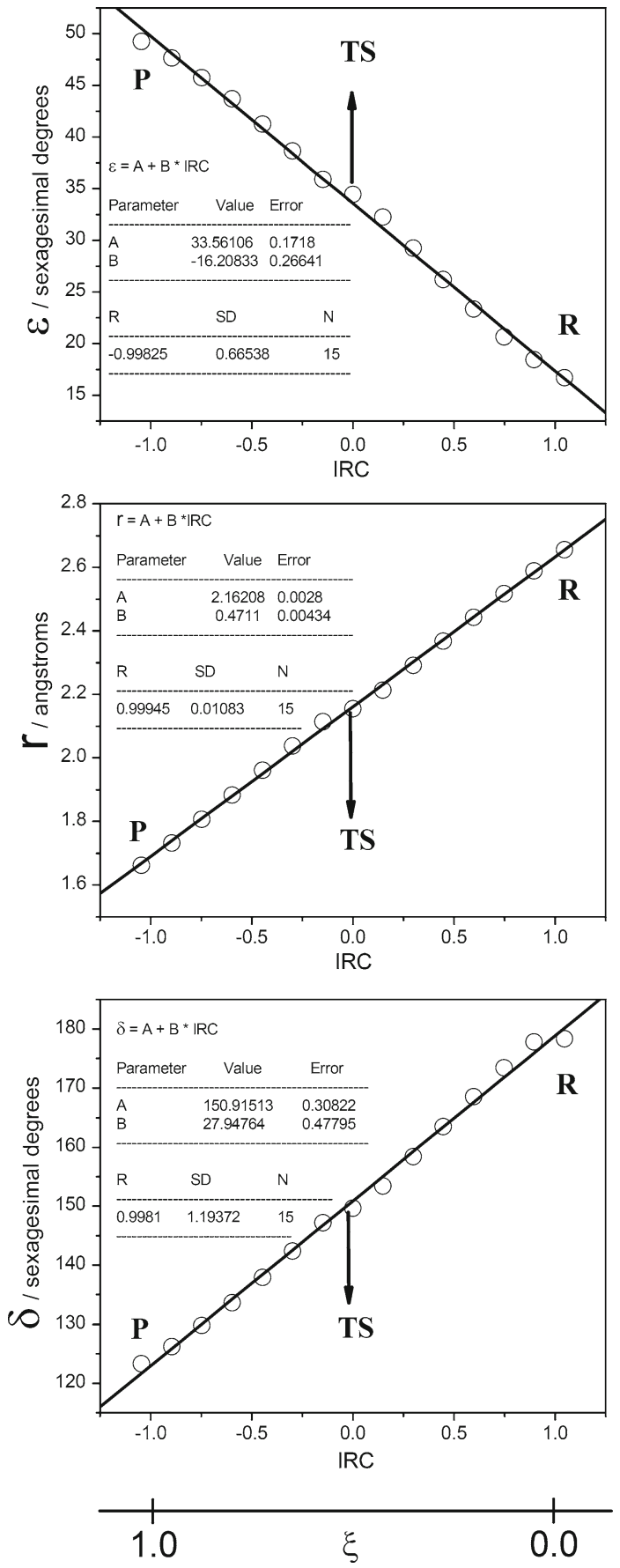